\title{
Response Response
}

\section{David Neumark}

Department of Economics and Economic Self-Sufficiency Policy Research Institute (ESSPRI), UCI, 3151 Social Science Plaza, Irvine, CA 92697, USA.

E-mail: dneumark@uci.edu

Eastern Economic Journal (2016) 42, 670-673. doi:10.1057/s41302-016-0014-9; published online 11 August 2016

Like earlier proponents of universal basic income policies, David Colander has proposed a "minimum-guaranteed jobs" policy that could replace both minimum wages and other income-support policies as a means of providing an income floor. The policy likely has some advantages relative to the minimum wage. But the advantages of minimumguaranteed jobs relative to income-support policies that provide a floor for family incomes are likely illusory, and indeed a minimum-guaranteed jobs policy could lead to substantially worse distributional outcomes.

In recent years, the push for higher minimum wages in the United States has been the principal policy response to increased income inequality and stagnation of wages at the bottom of the wage distribution. The arguments for and against a higher minimum wage are well known, and are relevant in assessing the "minimum-guaranteed jobs" policy. Minimum wages clearly lead to wage and income gains for many workers. However, a substantial body of evidence points to job loss for some of the least-skilled workers who are most affected, although this conclusion is contested. Even without job loss, the minimum wage is an inefficient distributional policy, as it regulates wages, not family income (or poverty). Because many minimum wage workers are very young, and because low employment and hours contribute importantly to poverty, the lion's share of benefits from a higher minimum wage do not go to poor or low-income families. Finally, fewer jobs for young workers can deter human capital accumulation through work experience, reducing the likelihood of low-skilled workers achieving economic self-sufficiency in the longer run. ${ }^{1}$

David Colander has proposed that we abandon minimum wages and instead rely on a "minimum jobs" guarantee, with the government serving as employer of last resort, offering jobs up to $40 \mathrm{~h}$ per week, paying $\$ 10$ per hour. Indeed, Colander argues that minimum-guaranteed jobs are also a better alternative than other income-support policies, because of the negative work incentives the latter policies create, and hence suggests that his minimum-guaranteed jobs proposal could replace both minimum wages and much of the remainder of the safety net.

Here are the key arguments offered: (1) unlike a minimum wage, a minimumguaranteed jobs program does not give employers incentives to use less low-skilled labor; (2) unlike income-support programs, minimum-guaranteed jobs do not create disincentives to work; and (3) minimum-guaranteed jobs will encourage employers to provide jobs that are attractive on many dimensions, to attract workers (essentially increasing the bargaining power of workers). 
Are minimum-guaranteed jobs a better idea than policies currently in place? Let's consider a number of issues:

Costs: Colander estimates the costs of three program components - direct labor costs, administration, and monitoring. He ignores the potential lost value of the private-sector jobs the minimum-guaranteed jobs program might displace. Even if some of these jobs are odious and/or pay low wages, the marginal workers in them presumably produce something close to the value of their wage, and the inframarginal workers produce surplus. It is conceivable that the minimum-guaranteed jobs would create value, perhaps even greater value if the labor is directed toward public goods and services that are underprovided by the private market. But Colander does not pretend this is likely, conceding that "the goal of these activities is not to produce usable output for society, but to provide working experiences by which people can translate their time into income." Moreover, although the public may view idleness as a waste of time and perhaps even an "evil," economists view leisure as contributing to utility and welfare, implying that the lost value of leisure relative to an income transfer program without work requirements is a significant cost.

Training: Colander suggests that minimum-guaranteed jobs could provide valuable skills that increase future wages. But our experience with training programs suggests that this is a hard goal to achieve even when training is the explicit goal. He also suggests that employers will be incentivized to offer jobs with more training in the private sector, to entice workers away from the minimum-guaranteed jobs. However, the prospect of a guaranteed job can reduce incentives for human capital investments by workers, so I do not think there is an unambiguous prediction of the sign of the effect of minimumguaranteed jobs on training. Moreover, I could easily envision adverse effects on the development of soft, noncognitive skills, if these are not needed to secure work. Colander suggests that those who do not meet behavioral standards will be fired, but it is unclear what incentive firms and organizations will have to do this, since the labor is free (and it is also unclear what happens to these workers afterward).

Distortions: Colander suggests that the minimum jobs policy works "with the market," whereas the minimum wage works "against the market." However, in competitive labor markets, the marginal value of a worker's time in production is equated with the marginal value of their leisure. Given that minimum-guaranteed jobs pay a wage above the productivity of some workers' time, the proposed policy also distorts behavior. The only interpretation I can give to minimum-guaranteed jobs working with the market is that they increase time spent working, in contrast to the opposite incentives of incomesupport programs (or the disemployment effects of minimum wages). There might be a philosophical argument for requiring work in exchange for benefits, but there is not an obvious economic one.

Labor supply vs. labor demand: The fundamental criticism of a higher minimum wage is that it reduces labor demand. But - again belying the notion that a minimum wage works against the market, whereas minimum-guaranteed jobs work with the market - a minimum-guaranteed jobs program will reduce labor supply to the private sector. This would increase wages and lower private-sector employment (or at least productive employment), possibly by more than the minimum wage reduces employment.

Distributional goals and work incentives: It is easy to look at our patchwork of income-support and related programs - SNAP, TANF, Medicaid, CHIP, housing, energy assistance, etc. - and not dream of a simplified unifying policy that could replace many of the adverse incentive effects and administrative costs of these programs. Indeed, that dream is likely fueling the revival of interest in universal basic income policies. But while this patchwork is less than ideal, it has evolved to address distributional concerns, 
with two overriding goals: a minimum level of family income; and adequate provision of food, income, health care, etc., to children in low-income families. These distributional goals are what leads to adverse incentive effects, because trying to target benefits to those who need help implies sharp changes in eligibility to try to exclude those who do not need help, lest program costs be prohibitive - a major problem with universal basic income.

The minimum-guaranteed jobs policy mitigates the cost problem with universal basic income, by paying benefits only to those likely to earn low wages (who choose to take these jobs) rather than to everyone. Yet it surely has worse distributional effects than our current safety net. Why guarantee a job at a given wage regardless of family income - for teenagers and single mothers alike? Of course the minimum wage, on its own, faces the same problem. But most of the other components of the safety net do a much better job of targeting those who need help.

Moreover, replacing income-support programs with minimum-guaranteed jobs could have some disastrous distributional consequences. Drawing the simple graph for the utility-maximizing labor supply choice makes this clear. If the only difference in the budget constraint is that getting "benefits" through the guaranteed job requires giving up $8 \mathrm{~h}$ of leisure a day, those with the highest value of time - likely parents with young children - are the ones most likely to forego the benefits and keep their leisure. In contrast, those with a low value of time are more likely to give up their leisure in return for the benefits. This implies that substituting a minimum-guaranteed jobs program for income-support programs will divert resources from families with children. (Note that this is not true of universal basic income policies.)

Overall assessment based on criteria for redistributional policy: This discussion of distributional issues emphasizes that although the minimum jobs proposal offers some advantages over the minimum wage, it is - like the minimum wage - barking up the wrong tree. Policymakers should be much more concerned with family income than individual wages, yet both policies target the latter. The rest of the safety net targets family income, despite being somewhat messy and uncoordinated, and creating work disincentives. I have three criteria for the kinds of policies we should adopt to counter rising income inequality, in light of which we can compare minimum-guaranteed jobs to minimum wages and the broader safety net.

First, redistributive policy should direct resources to the neediest. On this score, the minimum-guaranteed jobs idea has some merits over the minimum wage. By guaranteeing jobs and hours, it would provide help to some of those who are poor because they currently do not work or work low hours (and, unlike the minimum wage, would not create more of these). Nonetheless, minimum-guaranteed jobs would divert many resources to higher-income families. On this criterion, a minimum-guaranteed jobs policy might be superior to the minimum wage. However, it is inferior - and possibly vastly so - to income-support programs.

Second, redistributive policy should be paid for by those with the highest incomes. Because the minimum jobs policy would be publicly financed through taxes, it would be financed progressively, with those who earn the most (or at least, those who pay the most taxes) paying for the largest share of the program. This cannot be said of the minimum wage, which is paid for, first and foremost, by employers of low-skill labor - who may or may not be high income - and by everyone in terms of higher prices (with these price increases likely falling more heavily on the poor). However, income-support programs are also financed by taxes. Thus, on this criterion a minimum-guaranteed jobs policy is superior to the minimum wage, but no better than income-support programs. 
Third, redistributive policy should encourage rather than discourage human capital investment and work experience, to encourage economic self-sufficiency in the longer run. This may be the toughest challenge. Minimum wages reduce employment for young unskilled workers, with potentially negative long-run effects on earnings, and their effects on training are unsettled. Income-support programs create some work disincentives - unavoidably given the targeting goals - but may have longer-term beneficial effects via the resources that flow to children. Minimum-guaranteed jobs may or may not encourage human capital investment via training. They would, by definition, lead to the accumulation of more experience than would not working. However, the value of that experience might be questionable, and minimum-guaranteed jobs may divert far more people into unproductive employment than minimum wages remove from employment altogether. Thus, on this criterion it is unclear which policy is preferable - perhaps not surprising since the channels by which policy affects economic self-sufficiency in the longer run are numerous and complex.

\section{Note}

1. For a discussion of research on these points, and other references relevant to the findings discussed in this response, see: Neumark, David, 2016, "Policy Levers to Increase Jobs and Increase Income from Work after the Great Recession,” IZA Journal of Labor Policy, 5:6 (on-line). 